\title{
Phase I study of MLN8237-investigational Aurora A kinase inhibitor-in relapsed/refractory multiple myeloma, Non-Hodgkin lymphoma and chronic lymphocytic leukemia
}

\author{
Kevin R. Kelly • Thomas C. Shea • André Goy • Jesus G. Berdeja • Craig B. Reeder • \\ Kevin T. McDonagh • Xiaofei Zhou • Hadi Danaee • Hua Liu $•$ Jeffrey A. Ecsedy • \\ Huifeng Niu • Ely Benaim • Swaminathan Padmanabhan Iyer
}

Received: 16 September 2013 / Accepted: 8 November 2013 /Published online: 20 December 2013

(C) The Author(s) 2013. This article is published with open access at Springerlink.com

Summary Purpose Amplification or over-expression of the mitotic Aurora A kinase (AAK) has been reported in several heme-lymphatic malignancies. MLN8237 (alisertib) is a novel inhibitor of AAK that is being developed for the treatment of

\section{ClinicalTrials.gov identifier: NCT00697346}

Electronic supplementary material The online version of this article (doi:10.1007/s10637-013-0050-9) contains supplementary material, which is available to authorized users.

\section{K. R. Kelly}

CTRC at the University of Texas Health Science Center at San Antonio, The Institute for Drug Development, San Antonio, TX, USA

\section{T. C. Shea}

University of North Carolina, Chapel Hill, NC, USA

\section{A. Goy}

John Theurer Cancer Center, Hackensack University Medical Center,

Hackensack, NJ, USA

J. G. Berdeja

Sarah Cannon Research Institute, Nashville, TN, USA

C. B. Reeder

Division of Hematology and Medical Oncology, Mayo Clinic

Arizona, Scottsdale, AZ, USA

K. T. McDonagh

Markey Cancer Center, University of Kentucky, Lexington, KY, USA

X. Zhou $\cdot$ H. Danaee $\cdot$ H. Liu $\cdot$ J. A. Ecsedy $\cdot$ H. Niu $\cdot$ E. Benaim Takeda Pharmaceuticals International Company, Cambridge, MA, USA

\section{S. Padmanabhan Iyer $(\bowtie)$}

Houston Methodist Cancer Center, 6445 Main Street, Houston,

TX 77030, USA

e-mail: spiyer@houstonmethodist.org advanced malignancies. The objectives of this phase I study were to establish the safety, tolerability, and pharmacokinetic profiles of escalating doses of MLN8237 in patients with relapsed or refractory heme-lymphatic malignancies. Methods Sequential cohorts of patients received MLN8237 orally as either a powder-in-capsule (PIC) or enteric-coated tablet (ECT) formulation. Patients received MLN8237 PIC 25$90 \mathrm{mg}$ for 14 or 21 consecutive days plus 14 or 7 days' rest, respectively, or MLN8237 ECT, at a starting dose of $40 \mathrm{mg} /$ day once-daily (QD) for 14 days plus 14 days' rest, all in 28day cycles. Subsequent cohorts received MLN8237 ECT 30$50 \mathrm{mg}$ twice-daily (BID) for 7 days plus 14 days' rest in 21day cycles. Results Fifty-eight patients were enrolled (PIC $n=$ 28 , ECT $n=30$ ). The most frequent grade $\geq 3$ drug-related toxicities were neutropenia (45\%), thrombocytopenia (28\%), anemia (19\%), and leukopenia (19\%). The maximum tolerated dose on the ECT 7-day schedule was $50 \mathrm{mg}$ BID. The terminal half-life of MLN8237 was approximately $19 \mathrm{~h}$. Six $(13 \%)$ patients achieved partial responses and $13(28 \%)$ stable disease. Conclusion The recommended phase II dose of MLN8237 ECT is $50 \mathrm{mg}$ BID for 7 days in 21-day cycles, which is currently being evaluated as a single agent in phase II/III trials in patients with peripheral T-cell lymphoma.

Keywords Phase I-III Leukemia and lymphomas · Novel antitumor agent $\cdot$ Cell cycle mechanisms of anticancer drug action · Aurora A kinase inhibitor · MLN8237

\section{Introduction}

The cell cycle is a tightly regulated process that allows faithful inheritance of genetic material. Several kinase families including the Aurora family of serine/threonine kinases meticulously 
control the mitotic phase of the cell cycle. In particular Aurora A kinase (AAK) plays an essential role in chromosome alignment, centrosome separation and maturation, mitotic spindle formation, and cytokinesis during mitosis [1-3].

Amplification or over-expression of AAK has been reported in several heme-lymphatic malignancies [4-7], and Aurora $A$ may function as an oncogene through the induction of genetic instability and enhanced survival signaling $[8,9]$; increased Aurora A expression leads to enhanced cell survival [9]. AAK has also been shown to inhibit the post mitotic checkpoint by targeting p 53 for degradation leading to inhibition of p53-mediated apoptosis, and thereby bypassing cell cycle arrest which in turn is associated with genomic instability and oncogenic transformation $[10,11]$.

The fundamental role of AAK in cell cycle regulation and its aberrant expression in a broad range of malignancies prompted the development of agents that selectively inhibit its activity. Early studies showed that targeted knockdown of AAK led to accumulation of cells in the $\mathrm{G}_{2} / \mathrm{M}$ phase followed by apoptosis and was associated with in vitro and in vivo growth inhibition [12-14]. Inhibition of $A A K$ expression has also been shown to disrupt multiple events in mitosis, culminating in monopolar spindle formation, failure of centrosome separation, and incomplete cytokinesis $[3,15]$.

MLN8237 (alisertib) is an investigational, orally active, selective small molecule inhibitor of AAK that is being investigated for the treatment of both heme-lymphatic malignancies and solid tumors [16]. MLN8237 inhibits AAK with an inhibition constant (Ki) of $0.43 \mathrm{nM}$ [17] and is approximately 200 -fold more selective for AAK $\left(\mathrm{IC}_{50}=6.7 \mathrm{nmol} / \mathrm{L}\right)$ than Aurora B kinase $\left(\mathrm{IC}_{50}=1,534 \mathrm{nM} / \mathrm{L}\right)$ in cell-based assays [16]. Moreover, MLN8237 is selective for AAK over other kinases (at least 250-fold more selective in vitro) and receptors $[15,16,18,19]$. In both preclinical $[15,18,19]$ and clinical studies [20, 21], MLN8237 has shown preliminary antitumor activity in heme-lymphatic malignancies. Treatment of multiple myeloma (MM) cells with MLN8237 in vitro resulted in mitotic spindle abnormalities, mitotic accumulation, and apoptosis [15]. In a murine xenograft MM model, tumor burden was significantly reduced $(P=$ $0.007)$ and overall survival was significantly increased $(P=$ $0.0044)$ in animals treated with MLN8237 [15]. Furthermore, targeted inhibition of AAK with MLN8237 showed encouraging antitumor activity in preclinical models of lymphoma [22]. MLN8237 has also been shown to inhibit tumor growth in preclinical models of mantle cell lymphoma, the effect of which was potentiated by docetaxel, and vincristine and rituximab [22, 23]. In two phase I studies in patients with solid tumors, a range of doses and schedules were evaluated and the maximum tolerated dose (MTD) for MLN8237 was determined as $50 \mathrm{mg}$ twice-daily (BID) for 7-day schedule in 21-day cycles [17, 24].

This open-label, phase I study (NCT00697346) was performed to determine the dose-limiting toxicities (DLTs) and
MTD, and to evaluate the safety, pharmacokinetics (PKs), and preliminary antitumor activity of MLN8237 in patients with advanced heme-lymphatic malignancies (MM, nonHodgkin's lymphoma [NHL], and chronic lymphocytic leukemia [CLL]). Various dosing schedules of two formulations of MLN8237 were assessed in order to determine the optimal strategy to use clinically.

\section{Patients and methods}

Patients

Eligible patients were aged $\geq 18$ years and had: relapsed or refractory heme-lymphatic malignancy who had failed standard regimens; Eastern Cooperative Oncology Group performance status $0-2$; radiographically or clinically evaluable disease; absolute neutrophil count (ANC) $\geq 1,000 / \mathrm{mm}^{3}$ without growth factor support; platelet count $\geq 50,000 / \mathrm{mm}^{3}$ without transfusion requirement; creatinine clearance $\geq 30 \mathrm{~mL} /$ min; total bilirubin $\leq 1.5 \times$ upper limit of normal (ULN); and aspartate/alanine aminotransferase $\leq 2.5 \times \mathrm{ULN}$. Patients were excluded if they had received: significant enzyme inducers, enzyme-inducing antiepileptic drugs, or St John's wort within 14 days; systemic antineoplastic therapy or antineoplastic glucocorticoid treatment within 21 days; radiotherapy ( $\geq 25 \%$ of bone marrow) within 42 days; or radio-/toxinimmunoconjugates within 56 days; prior allogeneic bone marrow or other organ transplantation; proton pump inhibitors starting 4 days prior to cycle 1 . There was no restriction on the number of prior therapies. Patients were also excluded if they had known gastrointestinal disease that could interfere with oral absorption of MLN8237, conditions that could result in excessive daytime sleepiness, newly diagnosed or uncontrolled cancer-related central nervous system disease, or clinically significant electrocardiogram abnormalities.

\section{Study design and intervention}

This open-label, phase I study was conducted at 9 centers in the USA. The study was carried out in accordance with the Declaration of Helsinki and Good Clinical Practice guidelines. Institutional review boards and local independent ethics committees approved the study and all patients provided their written informed consent for participation.

Patients received escalating doses of MLN8237 as either a powder-in-capsule (PIC) or enteric-coated tablet (ECT) formulation in a standard $3+3$ design. Initially, only the PIC formulation of MLN8237 was available; the protocol was later modified to include assessment of the ECT formulation. Dosing schedules are summarized in Supplementary Fig. S1 (online only). The PIC formulation starting dose was 25 or $35 \mathrm{mg} /$ day. An initial loading dose was delivered BID on day 
1 of each cycle and patients subsequently received MLN8237 once daily (QD) on days 2-14 or 2-21, followed by 14 or 7 days' rest, respectively, in 28-day cycles. For the ECT formulation, the starting dose was $40 \mathrm{mg} /$ day QD for 14 days followed by 14 days' rest in 28-day cycles. Subsequent cohorts received MLN8237 ECT BID for 7 days followed by 14 days' rest in 21-day cycles.

Escalation to the next dose level proceeded only if DLTs were observed in $0 / 3$ or $1 / 6$ patients in cycle 1 . If 2 of the first 3-6 patients experienced DLTs at a given dose level, dose escalation was delayed while the available safety/clinical data were assessed and a decision made on how to proceed with a modified dose or schedule. In patients experiencing DLTs, the next cycle of MLN8237 administration was delayed and MLN8237 dose was reduced or discontinued accordingly at the Investigator's discretion. The use of myeloid growth factors (G-CSF or GM-CSF) or erythropoiesis-stimulating agents was permitted after the DLT evaluation period was completed (cycle 1) and on a case-by-case basis after cycle 2. Treatment continued for up to 12 months, or until disease progression or unacceptable toxicity, with the possibility of treatment extension beyond 12 months if clinical benefit was evident and toxicities were manageable.

\section{Endpoints}

This study had two primary endpoints: to determine the DLTs and MTD of orally administered MLN8237, and to estimate PK parameters during cycle 1 . PK parameters included: area under the plasma concentration versus time curve, maximum plasma concentration, time to maximum plasma concentration $\left(\mathrm{T}_{\max }\right)$, terminal half-life $\left(\mathrm{t}_{1 / 2}\right)$, accumulation ratio $\left(\mathrm{R}_{\mathrm{ac}}\right)$, and peak/trough ratio. Secondary endpoints were response rate, duration of response, and evaluation of banked tumor tissue samples for AAK protein expression and gene amplification.

Assessments

Safety

Adverse events (AEs) were graded by the National Cancer Institute-Common Terminology Criteria for Adverse Events v3.0 [25]. DLTs were defined as any of the following MLN8237-related AEs occurring during cycle 1: grade 4 neutropenia (ANC $<500 / \mathrm{mm}^{3}$ ) at any point during dosing and lasting $>7$ days during the recovery period, or with fever; grade 4 thrombocytopenia (platelet count $<25$, $000 / \mathrm{mm}^{3}$ ) at any point during dosing and lasting $>7$ days during the recovery period; grade 3 thrombocytopenia with clinically significant bleeding at any time; platelet count $<10,000 / \mathrm{mm}^{3}$ at any time; grade $\geq 3$ nausea and/or emesis despite optimal antiemetic prophylaxis; any other grade $\geq 3$ nonhematologic toxicity, with the exception of grade 3 arthralgia/myalgia, any grade of alopecia, or brief ( $<1$ week) grade 3 fatigue; a required rest period of $>21$ days due to an MLN8237-related toxicity; other grade $\geq 2$ nonhematologic toxicities that, in the opinion of the Investigator, required dose reduction or discontinuation of therapy with MLN8237.

\section{Response}

Response was evaluated according to the International Working Group criteria for patients with lymphoma [26, 27], the International Myeloma Working Group uniform response criteria for patients with MM [28], and the International Workshop on CLL guidelines [29].

\section{Pharmacokinetics}

MLN8237 plasma concentrations were measured using a validated liquid chromatography/tandem mass spectrometry assay. Plasma samples were collected in cycle 1 at various time points on the first day (day 1) and last day (day 7, ECT 7day schedule; day 14, PIC or ECT 14-day schedules; day 21, PIC 21-day schedule) of treatment. PK parameters were calculated by non-compartmental analysis using WinNonlin software (v5.2.1, Pharsight Corporation, Cary, NC).

\section{AAK protein expression and gene copy number determination}

AAK protein and the phosphorylated Histone $\mathrm{H} 3$ (pHH3) at serine 10 (Ser10) expression were determined from available patient archived tumor samples using immunohistochemistry (IHC). Aurora A gene and chromosome 20 copy number were determined using fluorescent in situ hybridization (FISH). IHC and FISH were carried out as described in Matulonis UA, et al. 2012 [30].

\section{Statistics}

Sample size was driven by the dose-escalation scheme and descriptive statistics were employed.

\section{Results}

Patients

A total of 58 patients were enrolled; 28 to MLN8237 PIC dose levels and 30 to MLN8237 ECT. Patient demographics and baseline characteristics are summarized in Table 1; median age was 61 years (range 27-82), $47 \%$ were male, and $90 \%$ were white. The most common tumor type was NHL $(n=36,62 \%)$, of which the most common subtypes were diffuse large B-cell lymphoma 
Table 1 Patient demographics and baseline characteristics
$A S C T$ autologous stem-cell transplant; $E B V$ Epstein-Barr virus; $E C O G$ Eastern Cooperative Oncology Group; ECT enteric-coated tablet; NHL non-Hodgkin lymphoma; PIC powder-incapsule

${ }^{\text {a }}$ Other types of NHL (each $n=1$ ) were: angio-immunoblastic T-cell lymphoma; nodal marginal zone B-cell lymphoma; EBV-positive T-cell lymphoma; marginal zone B-cell lymphoma transforming to diffuse large B-cell lymphoma; natural killer/T-cell lymphoma, nasal type; and small cell lympho$\mathrm{ma} /$ follicular lymphoma peripheral T-cell lymphoma - not otherwise specified
${ }^{\mathrm{b}}$ Both patients had noncutaneous

\begin{tabular}{|c|c|c|c|}
\hline & $\begin{array}{l}\text { MLN8237 PIC } \\
n=28\end{array}$ & $\begin{array}{l}\text { MLN8237 ECT } \\
n=30\end{array}$ & $\begin{array}{l}\text { Total } \\
N=58\end{array}$ \\
\hline Median age, years (range) & $62(41-74)$ & $57(27-82)$ & $61(27-82)$ \\
\hline Male, $n(\%)$ & $14(50)$ & $13(43)$ & $27(47)$ \\
\hline \multicolumn{4}{|l|}{ Race } \\
\hline White & $24(86)$ & $28(93)$ & $52(90)$ \\
\hline Black or African American & $3(11)$ & $1(3)$ & $4(7)$ \\
\hline Asian & 0 & $1(3)$ & $1(2)$ \\
\hline Not reported & 0 & $1(3)$ & $1(2)$ \\
\hline \multicolumn{4}{|l|}{ Tumor type, $n(\%)$} \\
\hline Non-Hodgkin lymphoma ${ }^{a}$ & $18(64)$ & $18(60)$ & $36(62)$ \\
\hline Diffuse large B-cell lymphoma & $9(32)$ & $7(23)$ & $16(28)$ \\
\hline Follicular lymphoma & $5(18)$ & $5(17)$ & $10(17)$ \\
\hline Mantle-cell lymphoma & $2(7)$ & 0 & $2(3)$ \\
\hline Peripheral T-cell lymphoma & 0 & $2(7)^{b}$ & $2(3)$ \\
\hline Multiple myeloma & $8(29)$ & $11(37)$ & $19(33)$ \\
\hline $\begin{array}{c}\text { Chronic lymphocytic leukemia/ } \\
\text { small lymphocytic leukemia }\end{array}$ & $2(7)$ & $1(3)$ & $3(5)$ \\
\hline $\begin{array}{l}\text { ECOG performance status } \\
0 / 1 / 2, n(\%)\end{array}$ & $5(18) / 17(61) / 6(21)$ & $8(27) / 16(53) / 6(20)$ & $13(22) / 33(57) / 12(21)$ \\
\hline \multicolumn{4}{|l|}{ Prior therapy, $n(\%)$} \\
\hline Radiation therapy & $11(39)$ & $14(47)$ & $25(43)$ \\
\hline ASCT & $12(43)$ & $11(37)$ & $23(40)$ \\
\hline$\geq 3$ prior systemic therapies, $n(\%)$ & $22(79)$ & $22(73)$ & $44(76)$ \\
\hline Primary refractory disease & $8(36)$ & $12(43)$ & $22(39)$ \\
\hline
\end{tabular}

On the ECT 14-day QD schedule, 2/6 patients who received MLN8237 $40 \mathrm{mg}$ experienced DLTs (1 patient with grade 4 febrile neutropenia; 1 with grade 4 bullous dermatitis and grade 4 neutropenia), and further dose escalation on this schedule was abandoned. On the ECT 7-day BID schedule, no DLTs were reported in the $30 \mathrm{mg}$ and $40 \mathrm{mg}$ cohorts; $1 / 10$ patients in the $50 \mathrm{mg}$ cohort experienced a DLT of grade 4 neutropenia. The MTD on the ECT 7-day BID schedule was therefore determined as $50 \mathrm{mg}$ BID (ie. $100 \mathrm{mg}$ total dose per day).

\section{DLTs and determination of MTD}

DLTs by MLN8237 dose and schedule are listed in Table 2. On the PIC 21-day QD schedule, 1/6 patients and 2/4 patients in the $25 \mathrm{mg}$ and $35 \mathrm{mg}$ dose levels, respectively, experienced DLTs, including grade $2 / 3$ neutropenia and grade 3 thrombocytopenia. On the PIC 14-day schedule, $0 / 3$ patients who received MLN8237 $35 \mathrm{mg}$ reported DLTs, and only $1 / 6$ who received $45 \mathrm{mg}$ experienced a DLT of grade 3 thrombocytopenia resulting in treatment discontinuation. At $65 \mathrm{mg}, 0 / 3$ patients experienced a DLT and at $90 \mathrm{mg}, 2 / 2$ patients experienced a DLT. The dose was de-escalated to $65 \mathrm{mg}$ and 4 additional patients were enrolled, 2 of whom experienced DLTs (grade 4 neutropenia and grade 4 thrombocytopenia). The MTD on the PIC 14-day schedule was determined to be $45 \mathrm{mg}$ QD.

\section{Safety}

All 58 patients were included in the safety population. The safety profile for both MLN8237 formulations is summarized in Supplementary Table S1 (online-only). All patients experienced at least 1 treatment-emergent $\mathrm{AE}$, and $90 \%$ reported drug-related AEs. Common all-grade and grade $\geq 3$ drugrelated AEs are summarized in Table 3. In total, 35 (60\%) patients (PIC $n=14$, ECT $n=21$ ) reported grade $\geq 3$ drugrelated AEs, the most common of which were neutropenia (45\%), and thrombocytopenia (28\%). While frequencies of myelotoxicity somewhat differed between patient groups enrolled to the ECT versus PIC formulations (Table 3), quantitative comparisons are confounded by both the different doses 
Table 2 DLTs reported in patients receiving MLN8237 treatment
$B I D$ twice daily; $D L T$ dose-limiting toxicity; $E C T$ enteric-coated tablet; $P I C$ powder-in-capsule; $Q D$ once daily

\begin{tabular}{|c|c|c|c|c|}
\hline Schedule & Dose level & $N$ & Patients with DLT, n & Description of DLTs observed in each patient \\
\hline \multirow[t]{3}{*}{ PIC 21-day } & $25 \mathrm{mg}$ QD & 6 & 1 & $\begin{array}{l}\text { Grade } 2 \text { neutropenia, grade } 3 \text { thrombocytopenia, } \\
\text { grade } 3 \text { neutropenia }\end{array}$ \\
\hline & $35 \mathrm{mg}$ QD & 4 & 2 & $\begin{array}{l}\text { Grade } 3 \text { neutropenia, grade } 3 \text { thrombocytopenia } \\
\text { resulting in treatment discontinuation }\end{array}$ \\
\hline & & & & $\begin{array}{l}\text { Grade } 3 \text { neutropenia resulting in treatment } \\
\text { discontinuation }\end{array}$ \\
\hline
\end{tabular}

$\begin{array}{llll}\text { PIC 14-day } & 35 \mathrm{mg} \text { QD } & 3 & - \\ 45 \mathrm{mg} \text { QD } & 6 & 1 \\ & & & \\ 65 \mathrm{mg} \text { QD } & 7 & 2 \\ & & & \\ & & & \\ & & & \\ \text { ECT 14-day } & 40 \mathrm{mg} \text { QD } & 6 & 2\end{array}$

Grade 3 thrombocytopenia resulting in treatment discontinuation

Grade 4 thrombocytopenia

Grade 4 neutropenia

Grade 3 febrile neutropenia

Grade 4 thrombocytopenia

Grade 4 febrile neutropenia

Grade 4 bullous dermatitis resulting in treatment discontinuation, grade 4 neutropenia

Grade 4 neutropenia and schedules administered with the two formulations, and potential effects of differing baseline marrow reserves. For example, most patients received the ECT formulation BID for 7 days whereas those receiving MLN8237 PIC received it BID on day 1 only and QD thereafter. The effect of a higher total dose of MLN8237 over a shorter time period probably accounts for the higher rates of neutropenia and thrombocytopenia in the ECT group.

Twenty-eight (48\%) patients (PIC $n=12$, ECT $n=16$ ) experienced serious AEs, the most common of which was febrile neutropenia (PIC $n=1$, ECT $n=4)$. In total, $9(16 \%)$ patients (PIC $n=4$, ECT $n=5$ ) discontinued treatment due to

Table 3 Most frequent drug-related AEs in $\geq 10 \%$ (any grade) or $\geq 5 \%$ (grade $\geq 3$ ) of patients in the overall population

\begin{tabular}{|c|c|c|c|c|c|c|c|c|c|}
\hline \multirow[t]{3}{*}{$\mathrm{AE}, n(\%)$} & \multicolumn{2}{|c|}{ MLN8237 PIC } & \multicolumn{2}{|c|}{ MLN8237 ECT } & \multicolumn{3}{|c|}{ MLN837 ECT at MTD* } & \multirow{2}{*}{\multicolumn{2}{|c|}{$\frac{\text { Total }}{N=58}$}} \\
\hline & \multicolumn{2}{|l|}{$n=28$} & \multicolumn{2}{|l|}{$n=30$} & \multicolumn{3}{|l|}{$n=10$} & & \\
\hline & All grades & Grade $\geq 3$ & All grades & Grade $\geq 3$ & All grades & Grade 3 & Grade 4 & All grades & Grade $\geq 3$ \\
\hline Neutropenia & $13(46)$ & $10(36)$ & $20(67)$ & $16(53)$ & $7(70)$ & $3(30)$ & $2(20)$ & $33(57)$ & $26(45)$ \\
\hline Thrombocytopenia & $11(39)$ & $8(29)$ & $13(43)$ & $8(27)$ & $5(50)$ & - & $2(20)$ & $24(41)$ & $16(28)$ \\
\hline Diarrhea & $8(29)$ & - & $12(40)$ & $1(3)$ & $4(40)$ & - & - & $20(34)$ & $1(2)$ \\
\hline Anemia & $8(29)$ & $4(14)$ & $11(37)$ & $7(23)$ & $4(40)$ & $2(20)$ & $1(10)$ & $19(33)$ & $11(19)$ \\
\hline Fatigue & $9(32)$ & $2(7)$ & $6(20)$ & - & $1(10)$ & - & - & $15(26)$ & $2(3)$ \\
\hline Vomiting & $6(21)$ & - & $2(7)$ & - & - & - & - & $8(14)$ & - \\
\hline Alopecia & $4(14)$ & - & $11(37)$ & - & $4(40)$ & - & - & $15(26)$ & - \\
\hline Leukopenia & $3(11)$ & $2(7)$ & $10(33)$ & $9(30)$ & $4(40)$ & $2(20)$ & $2(20)$ & $13(22)$ & $11(19)$ \\
\hline Nausea & $9(32)$ & - & $3(10)$ & - & - & - & - & $12(21)$ & - \\
\hline Lymphopenia & $2(7)$ & - & $6(20)$ & $4(13)$ & $2(20)$ & $1(10)$ & $1(10)$ & $8(14)$ & $4(7)$ \\
\hline Stomatitis & $2(7)$ & $1(4)$ & $5(17)$ & - & $1(10)$ & - & - & $7(12)$ & $1(2)$ \\
\hline Somnolence & $1(4)$ & - & $5(17)$ & - & $2(20)$ & - & - & $6(10)$ & - \\
\hline Decreased WBC count & $1(4)$ & $1(4)$ & $4(13)$ & $2(7)$ & $2(20)$ & $2(20)$ & - & $5(9)$ & $3(5)$ \\
\hline Febrile neutropenia & $1(4)$ & $1(4)$ & $4(13)$ & $4(13)$ & $2(20)$ & $1(10)$ & $1(10)$ & $5(9)$ & $5(9)$ \\
\hline
\end{tabular}

*MTD, $50 \mathrm{mg}$ BID

$A E$ adverse event; $E C T$ enteric-coated tablet; $M T D$ maximum tolerated dose; PIC powder-in-capsule; WBC white blood cell 
Fig. 1 Mean plasma concentration-time profiles of MLN8237 (ECT formulation, 7day BID schedule) on days 1 and 7 (first dose). BID twice daily; ECT enteric-coated tablet
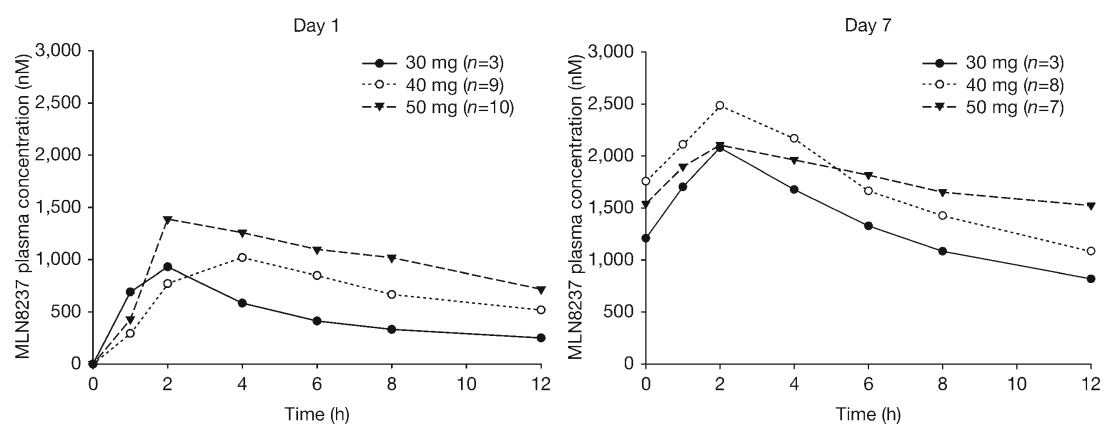

AEs of which thrombocytopenia $(n=4)$, neutropenia, bullous dermatitis $(n=1)$, and confusion $(n=1)$ were drug-related.

There were $6(10 \%)$ on-study deaths (deaths occurring during treatment or within 30 days of last dose); none of which were considered treatment-related. In the PIC population, the 3 reported deaths were due to renal failure, an acute exacerbation of obstructive airways disorder, and progressive lymphoma. In the ECT population, the 3 reported deaths were due to progressive $\mathrm{MM}(n=2)$ and hypercalcemia in a patient with DLBCL.

\section{Pharmacokinetics}

Mean plasma concentration-time profiles for MLN8237 ECT BID on days 1 and 7, are shown in Fig. 1. The summary statistics of PK parameters for this dosing regimen are presented in Supplementary Table S2 (online only).

An integrated assessment of the PK parameters was performed across dose cohorts in all 58 patients who received either the PIC or ECT formulation of MLN8237. The validity of this assessment was supported by the lack of a readily apparent nonlinearities in the PK of MLN8237 and the lack of a readily apparent effect of formulation on overall mean apparent oral clearance $\left(\mathrm{CL}_{\mathrm{ss}} / \mathrm{F}\right.$; mean $\mathrm{CL}_{\mathrm{ss}} \mathrm{F} ; 4.5$ and $5 \mathrm{~L} / \mathrm{h}$ for MLN8237 PIC or ECT, respectively). MLN8237 absorption was rapid, with an overall median $\mathrm{T}_{\max }$ of 2 and $2.6 \mathrm{~h}$ following oral administration of MLN8237 PIC or ECT, respectively. The overall mean steady-state $t_{1 / 2}$ following multiple-dose administration was approximately $19 \mathrm{~h}$ (range: $10-43 \mathrm{~h}$ ). The $\mathrm{R}_{\mathrm{ac}}$ ratio was 2.5 for BID dosing (coefficient of variation $[\mathrm{CV} \%$ ]: $35 \%, n=18)$. Mean $\mathrm{CL}_{\mathrm{ss}} / \mathrm{F}$ was $4.8 \mathrm{~L} / \mathrm{h}$ (CV \%: $69 \%, n=42$ ).

\section{Antitumor activity}

Forty-seven patients were response-evaluable; 6 patients had a partial response (PR) and 13 had stable disease (SD) for 1.911.0 months (Fig. 2). Scans for a heavily pre-treated patient with relapsed DLBCL who achieved PR are shown in Fig. 3, along with additional details regarding all 6 patients with PR.
Aurora A protein expression and gene copy number

AAK and pHH3(Ser10) (used as a marker for the incidence of mitotic cells) protein expression were determined by IHC using available archived tumor biopsies $(n=22)$ collected from patients prior to enrollment in this study (Fig. $4 \mathrm{a}$ and b). Of these, 3 response-evaluable patients showed a marked increase in AAK protein levels; 2 of these patients (1 with peripheral Tcell lymphoma- not otherwise specified [PTCL-NOS] and the other with FL) had a PR as best response and the third patient (with EBV-positive T-cell lymphoma), experienced progressive disease. These patients showed variable incidence of mitotic cells (based on pHH3(Ser10) expression levels) and there was no apparent correlation with clinical response (Fig. 4b). Aurora $A$ gene and chromosome 20 copy numbers were evaluated by FISH in 11 response-evaluable patients. In 2 of these patients, 1 with T-cell lymphoma and the other with angioimmunoblastic T-cell lymphoma, the analyzed tumors showed an increase in Aurora A gene copy number (Fig. 4c). Interestingly tumor samples from the patient with T-cell lymphoma also showed an increase in Aurora A protein levels. In all analyzed samples the Aurora A/chromosome 20 ratio was close to 1, suggesting that the increased Aurora A gene copy number in the 2 patients was due to amplification of chromosome 20 (Fig. 4d).

\section{Discussion}

This was the first phase I study to evaluate the safety and PKs of the investigational AAK inhibitor MLN8237 as PIC or ECT formulations in patients with advanced heme-lymphatic malignancies. Previous studies have shown that doses of

Fig. 2 MLN8237 exposure and response in a all response-evaluable patients and $\mathbf{b}$ all response-evaluable patients with lymphomas. Largest percent change in target lesions in patients with lymphoma is shown in panel c. AITL angioimmunoblastic T-cell Lymphoma; $C L L$ chronic lymphocytic leukemia; $D L B C L$ diffuse large B-cell lymphoma; $E B V$ $T C L$ Epstein-Barr virus-T cell lymphoma; $F L$ follicular lymphoma; $M C L$ mantle cell lymphoma; $M M$ multiple myeloma; $M Z L$ marginal zone B-cell lymphoma; NK/TCL natural killer/T-cell lymphoma; $P D$ progressive disease; $P R$ partial response; $P T C L-N O S$ peripheral T-cell lymphoma- not otherwise specified; $S C L$ small cell lymphoma; $S L L$ small lymphocytic leukemia 
a
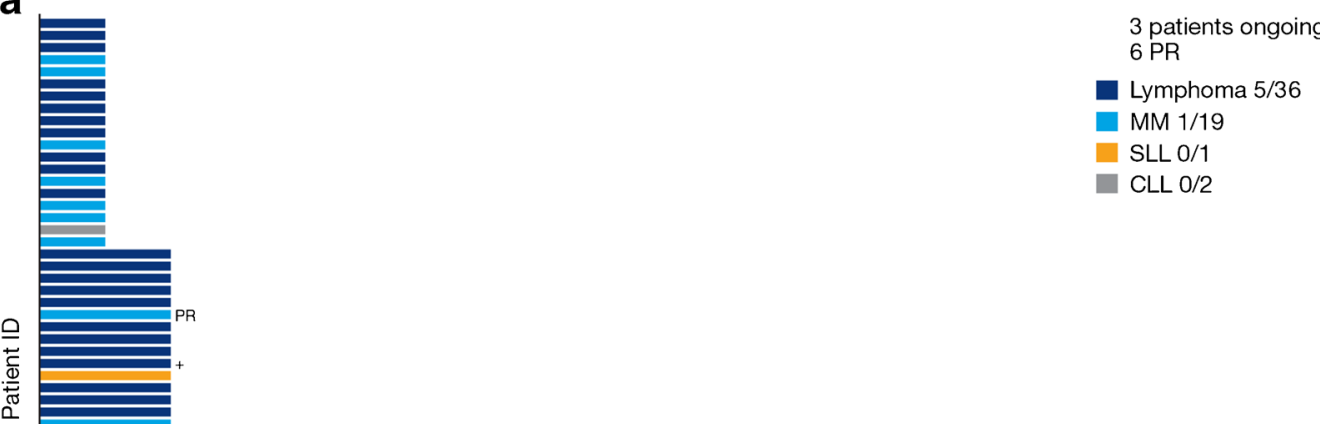

으

离
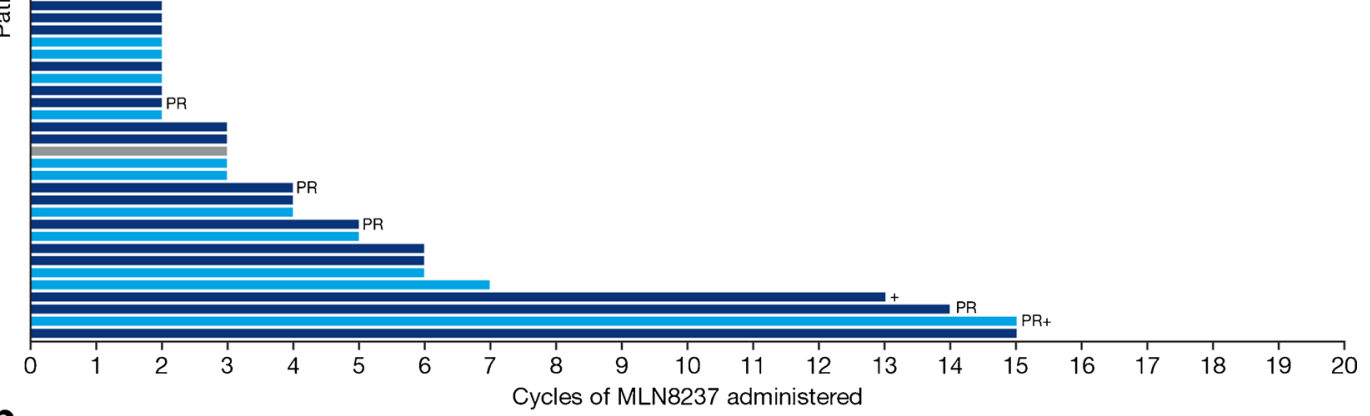

b

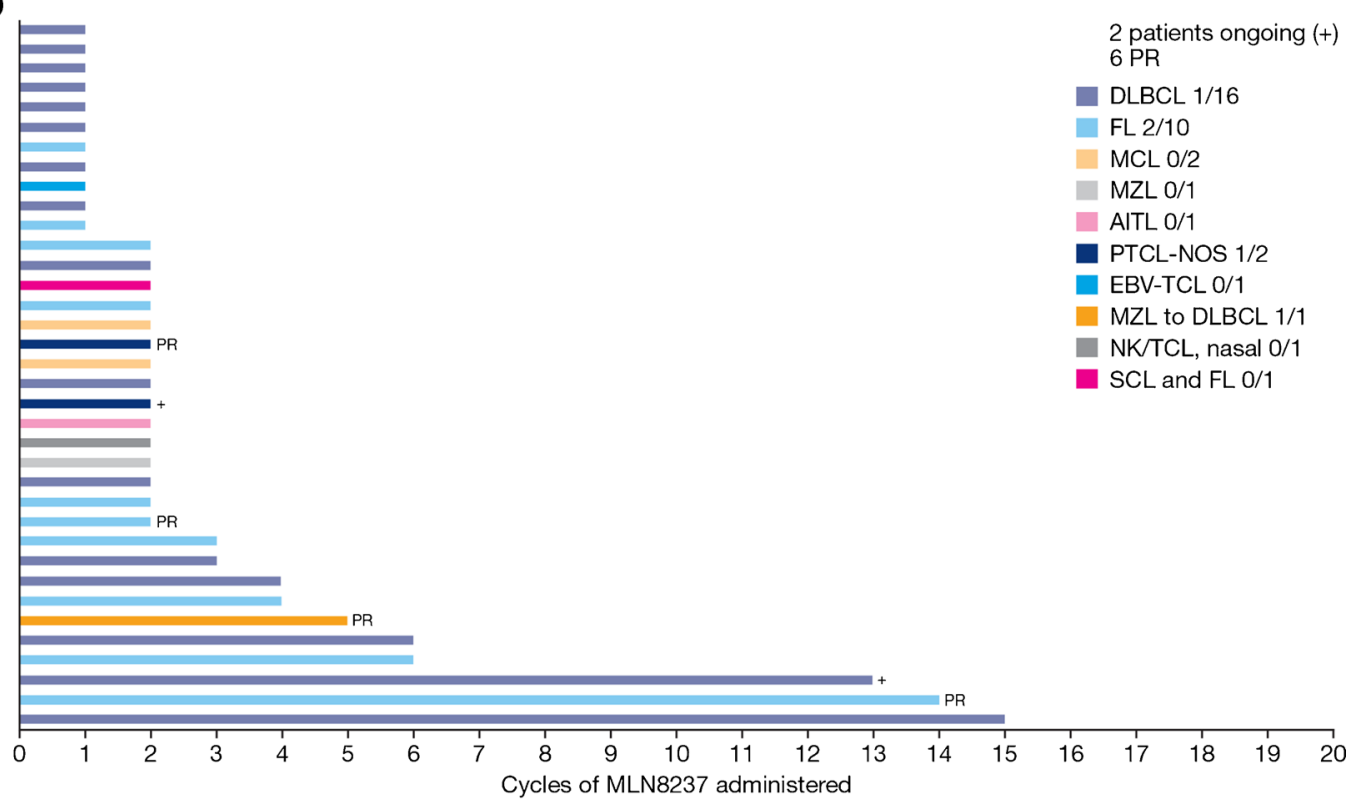

C

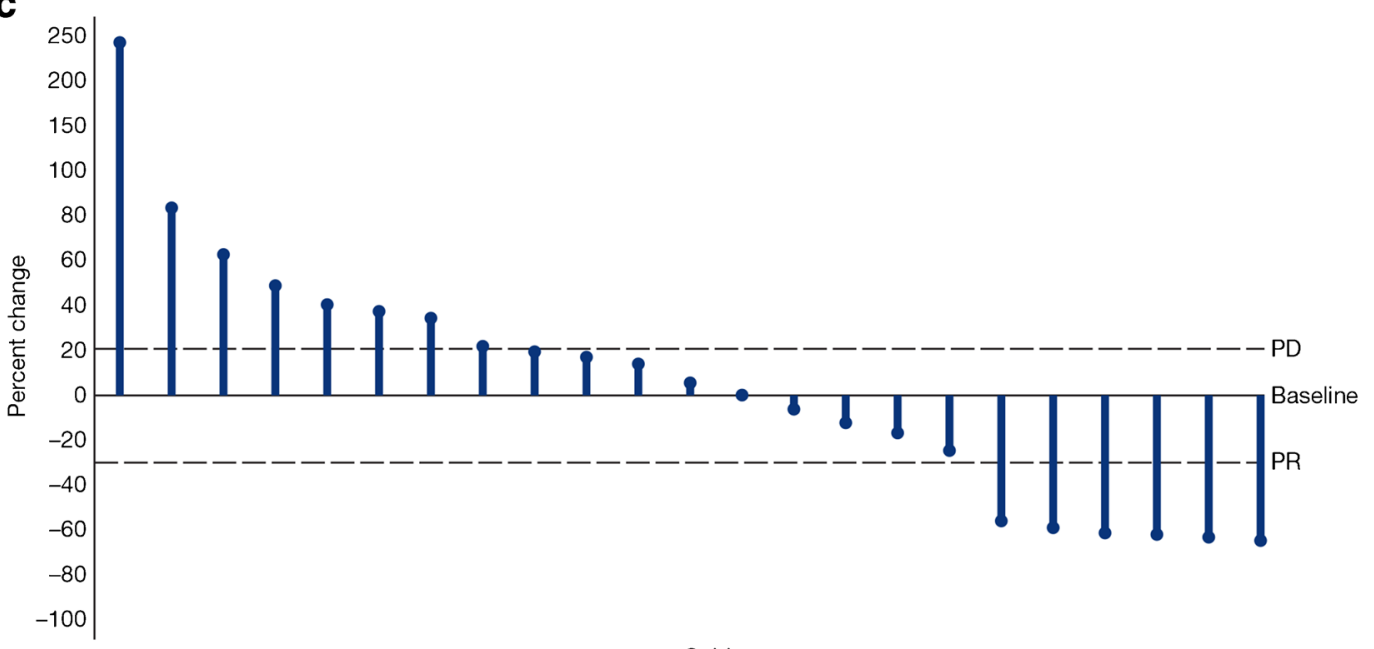

Subject 
Fig. 3 Antitumor activity in a patient with diffuse large B-cell lymphoma receiving $65 \mathrm{mg}$ MLN8237 PIC QD 14-day (Top). Tumor type, MLN8237 treatment regimen and additional details for all 6 patients who achieved a PR (Bottom). BEAM carmustine, etoposide, cytarabine, melphalan; $B I D$ twice daily; $E C T$ enteric coated tablet; PIC powder-incapsule; $P R$ partial response; $Q D$ once daily
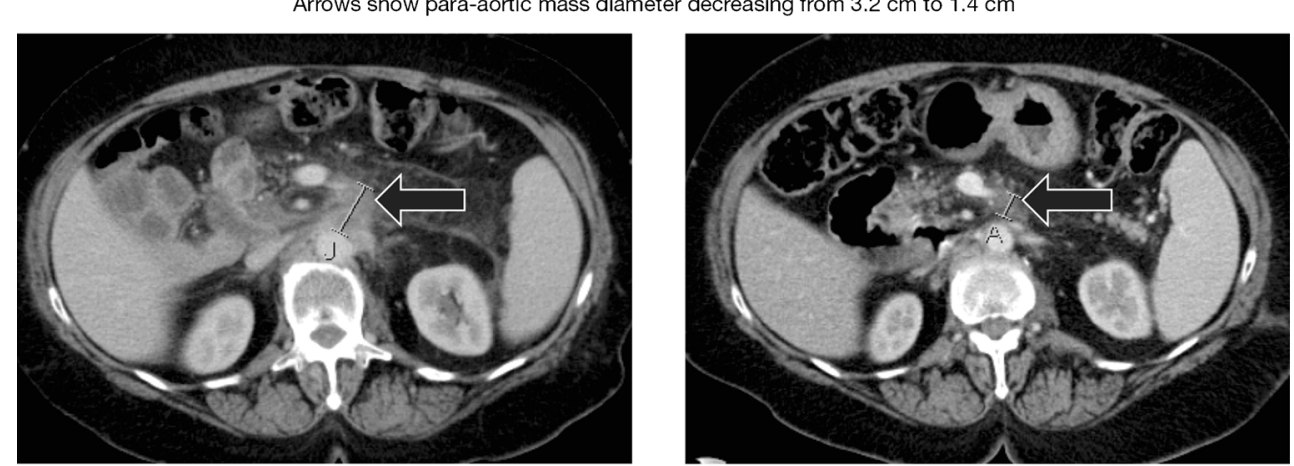

Scans kindly provided by the NC Cancer Hospital

\section{Tumor type \\ Relapsed diffuse large B-cell lymphoma}

MLN8237 regimen

MLN8237 PIC $65 \mathrm{mg}$ QD on the 14-day schedule, which was then reduced to $45 \mathrm{mg}$ QD to manage toxicities
Details

Heavily pre-treated patient (prior therapies included etoposide, ifosfamide, methylprednisolone, carboplatin, cytarabine, and cisplatin); high dose therapy prior to transplant, BEAM; Ki-67 staining, $90 \%$ of tumor cells; non-bulky disease

PR first documented in cycle 4 (shown above)

\begin{tabular}{lll}
\hline $\begin{array}{l}\text { Marginal zone B-cell lymphoma } \\
\text { transforming to diffuse large B-cell } \\
\text { lymphoma }\end{array}$ & PIC $65 \mathrm{mg}$ 14-day schedule & PR first documented in cycle 5 \\
\hline Multiple myeloma & $\begin{array}{l}\text { MLN8237 ECT } 40 \mathrm{mg} \text { BID on the 7-day } \\
\text { schedule }\end{array}$ & $\begin{array}{l}\text { PR for }>4 \text { months duration, first } \\
\text { observed in cycle 4 }\end{array}$ \\
\hline Folllicular Lymphoma & $\begin{array}{l}\text { MLN8237 PIC } 35 \mathrm{mg} \mathrm{QD} \text { on the 14-day } \\
\text { schedule }\end{array}$ & $\begin{array}{l}\text { PR for }>3 \text { months that was first } \\
\text { observed in cycle 10 }\end{array}$ \\
\hline Folllicular Lymphoma & $\begin{array}{l}\text { MLN8237 ECT } 50 \mathrm{mg} \text { BID on the 7-day } \\
\text { schedule }\end{array}$ & PR first documented in cycle 2 \\
\hline Peripheral T-cell lymphoma & $\begin{array}{l}\text { MLN8237 ECT } 50 \mathrm{mg} \text { BID on the 7-day } \\
\text { schedule }\end{array}$ & PR first documented in cycle 2 \\
\hline
\end{tabular}

MLN8237 25-70 mg for 21 days were associated with predominantly hematologic DLTs $[17,24,31]$. On the other hand, higher daily doses administered over shorter treatment periods such as 7 days have been shown to be generally tolerable [17, 24]. The MTD of single-agent MLN8237 in this patient population with heme-lymphatic malignancies was $45 \mathrm{mg}$ QD on a 14-day schedule for the PIC formulation and $50 \mathrm{mg}$ BID on a 7day schedule for the ECT formulation. The same MTD for the 7-day BID schedule was defined in two previous phase I studies of MLN8237 PIC [17, 24] and ECT [17] in patients with advanced solid tumors. The ECT formulation has been chosen for future development as it allows MLN8237 (an acidic drug with low aqueous solubility) to bypass stomach acid (gastric $\mathrm{pH}, 1-4)$ and delays dissolution until delivery to the small intestine $[16,17]$.

In the present study, MLN8237 was generally well tolerated. Common side effects included hematologic AEs, gastrointestinal AEs, and alopecia. In general, significant cumulative toxicities were not observed, and the most frequently occurring toxicities were generally reversible in the recovery period between cycles. Although grade 3 or higher neutropenia was reported with high frequency ( $45 \%$ ) across all cohorts, the frequency of grade 3 or higher febrile neutropenia was $9 \%$.
Grade 4 neutropenia was only seen in $1 / 10$ patients treated at the MTD dose of $50 \mathrm{mg}$ BID for the ECT formulation.

The PK properties of MLN8237 in patients with hemelymphatic malignancies were generally consistent with those observed in a previous study of patients with advanced solid tumors [17]. Based on the integrated PK assessment across dose cohorts in all 58 patients, the range of apparent oral clearance of MLN8237 observed following administration as the ECT formulation was comparable to that observed following administration as PIC, supporting the conclusion of achievement of similar systemic exposures following administration as either the ECT or PIC formulation. This observation is also consistent with results from the bioavailability part of the study, which showed that the bioavailabilities of MLN8237 PIC and ECT were similar [17].

Increased levels of Aurora A protein were observed in 3 response evaluable patients among 22 available archived tumor biopsies. Of note, 2 of these patients had PRs whereas 1 patient experienced progressive disease. In addition, 2 patients had amplified Aurora A gene copy number. Aurora A amplification in these tumors was most likely due to increased chromosome 20 copy number as the Aurora A/chromosome 20 ratio was close to 1 . 

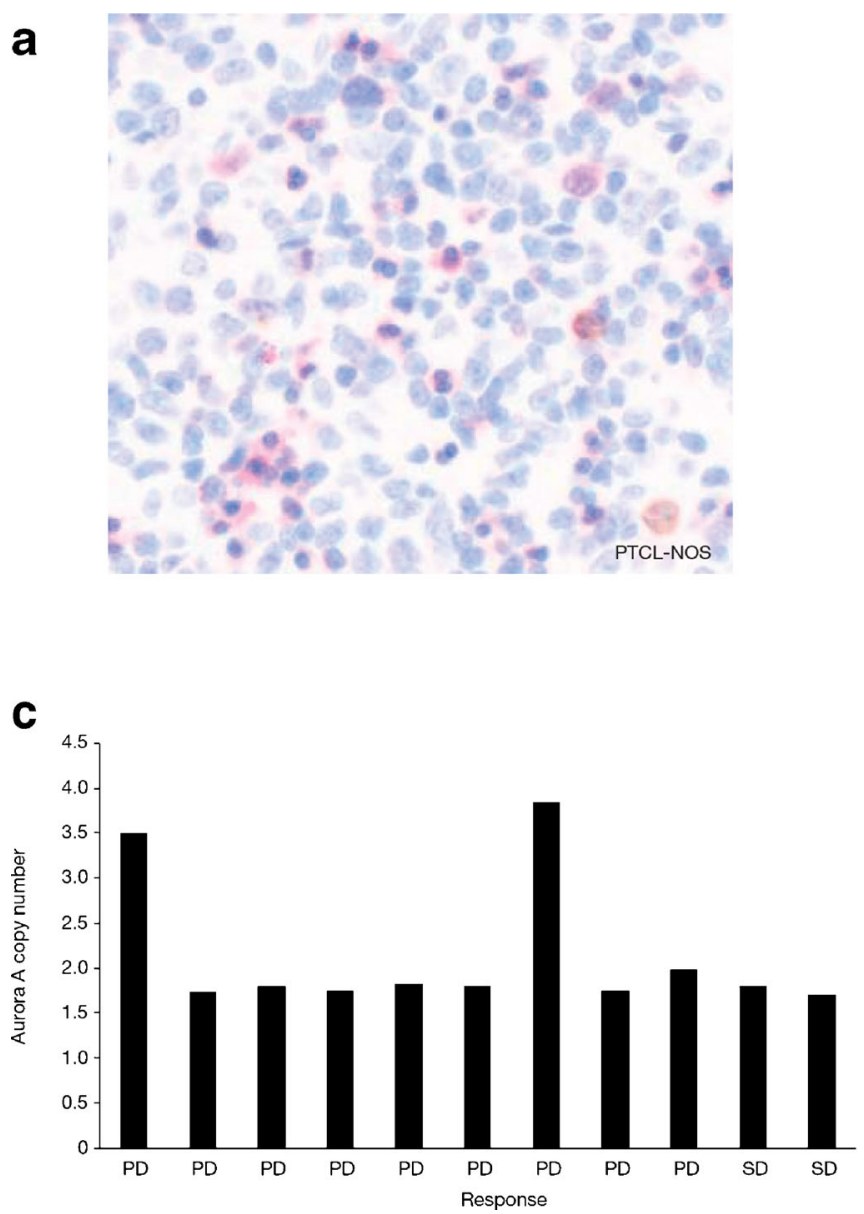

Fig. 4 Aurora A and pHH3(Ser10) expression and Aurora A gene copy number inavailable archived tumors. IHC analysis of Aurora A protein expression in a PTCL-NOS sample (a). Percentage of cells positive for Aurora A and pHH3 revealed by IHC (b). FISH analysis of Aurora A gene copy number (c). Ratio of Aurora A gene copy number relative to

Aurora A protein overexpression and gene amplification have been linked to the etiology of a variety of cancers, including heme-lymphatic malignancies [4-7]. The number of response evaluable patients with available and informative archived tumor samples was too small to determine if there was a correlation between Aurora A protein expression and gene copy number with MLN8237 response. Identifying biomarkers predictive of response to Aurora kinase inhibitors has been challenging and larger studies will be needed to determine if tumor Aurora A expression or gene amplification correlates with response [32].

MLN8237 has also shown potential antitumor activity in a recent phase II study of single-agent MLN8237 (50 mg BID) in patients with aggressive B- and T-cell NHL [20]. The overall response rate in all 48 treated patients was $27 \%$ (10\% CR and $17 \%$ PR), with $33 \%$ of patients achieving SD. Of particular note, $4 / 8$ patients with T-cell lymphoma had a response [20]. While not a primary focus of the study, the preliminary antitumor activity seen here warrants further
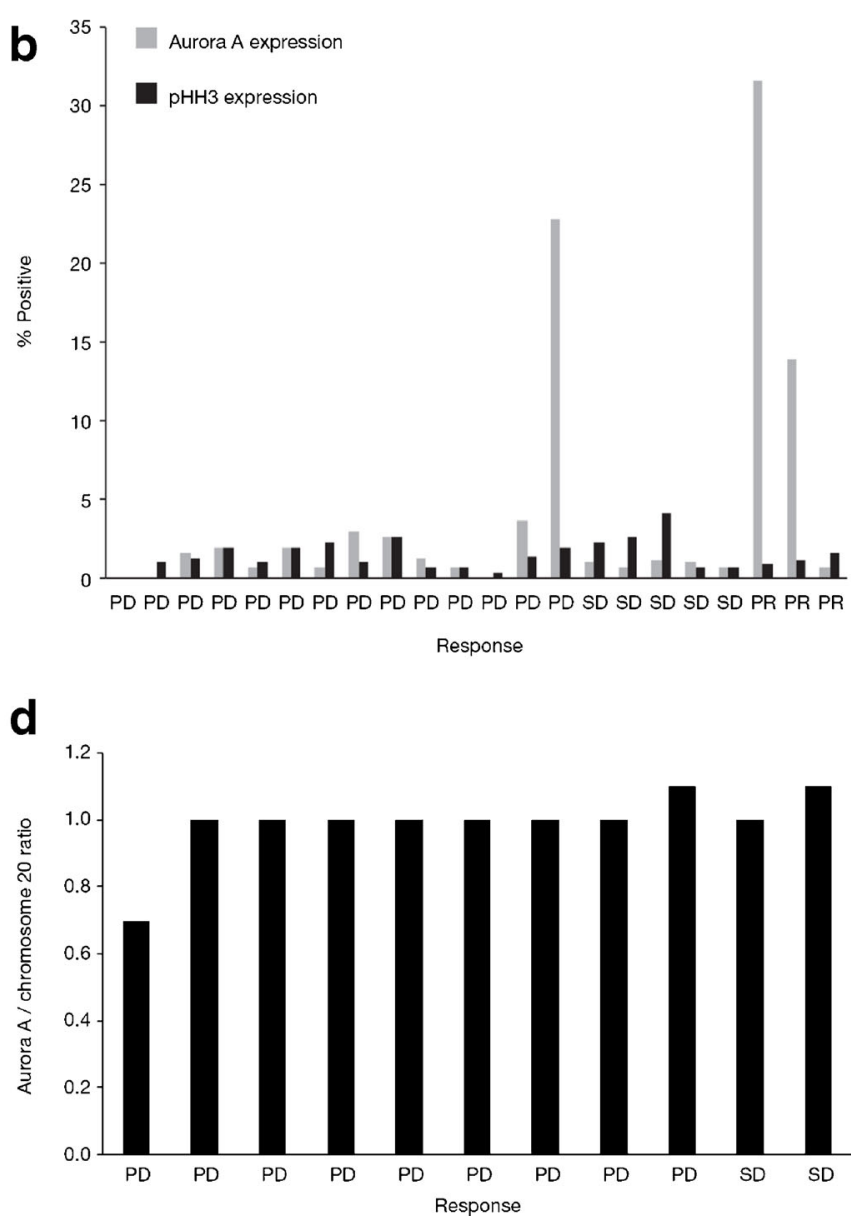

chromosome 20 gene copy number (d). FISH fluorescent in situ hybridization; IHC immunohistochemistry; $\mathrm{pHH}$ (Ser 10) phosphorylated Histone $\mathrm{H} 3$ at serine $10 ; P D$ progressive disease; $P R$ partial response; $P T C L$ NOS peripheral T-cell lymphoma- not otherwise specified; $S D$ stable disease

investigation. MLN8237 showed signs of antitumor activity as a single agent in patients with advanced heme-lymphatic malignancies including MM, DLBCL, FL, and PTCL. Six (13\%) patients (2 with FL, 1 each with DLBCL, marginal zone B-cell lymphoma transformed to DLBCL, MM, and PTCL) who had each received several prior therapies achieved a PR, and 13 (28\%) achieved SD.

Taken together, these results support further evaluation of the safety and antitumor activity of MLN8237 in NHL and MM in appropriately designed clinical studies. Based on the results of this study and an initial phase II study of MLN8237 in patients with lymphoma [20], a phase II (SWOG S1108; NCT01466881 - accrual complete) and a randomized phase III trial of single-agent MLN8237 compared with investigator's choice of pralatrexate, romidepsin, or gemcitabine in relapsed or refractory PTCL (NCT01482962) is now underway. The rationale for evaluating the clinical activity of MLN8237 in T-cell lymphomas is further supported by recent preclinical studies showing that both AAK and Aurora B 
kinase are expressed in T-cell lymphoma cell lines [33] and in patient samples from the SWOG S0350 study [34], and that MLN8237 induces endo-reduplication and apoptosis in PTCL cell lines [33]. In addition, based on evidence that MLN8237 combined synergistically with rituximab and vincristine in preclinical models of lymphoma [22], a phase I/II trial of MLN8237 in combination with rituximab and vincristine in patients with relapsed or refractory aggressive B-cell lymphoma is also underway (NCT01397825).

In conclusion, the recommended phase II dose for MLN8237 is $50 \mathrm{mg}$ BID for 7 days followed by a 14-day recovery period, in 21-day cycles. MLN8237 was generally tolerated in these patients with advanced heme-lymphatic malignancies. Preliminary antitumor activity was observed in patients with refractory NHL and MM. MLN8237 continues to be evaluated as a single agent and in combination with other agents in relapsed or refractory NHL.

Acknowledgments The authors would like to thank the patients who participated in this study and their families as well as staff at all investigational sites; Stephanie Hodges and Kathleen Cobb at CTRC, San Antonio for Study Co-ordination.

The authors would also like to acknowledge Nadia Korfali of FireKite for writing assistance in the development of this manuscript, which was funded by Millennium: The Takeda Oncology Company.

Ethical standards The study was carried out in accordance with the Declaration of Helsinki and Good Clinical Practice guidelines. Institutional review boards and local independent ethics committees approved the study and all patients provided their written informed consent for participation.

Disclosures Employment: XZ, HD, HL, JAE, HN, EB (Takeda Pharmaceuticals International Company).

Ownership interest: HD, EB (Takeda Pharmaceuticals International Company).

Research Funding: TS, AG, SPI, KTM (Millennium: The Takeda Oncology Company); CBR (Celgene, Millennium: The Takeda Oncology company, Novartis).

Honoraria: AG (Speakers bureau and advisory committee, Millennium: The Takeda Oncology Company)

Consultancy or advisory role: $\mathrm{KK}, \mathrm{AG}$ (Millennium: The Takeda Oncology Company); TS (Spectrum Pharmaceuticals, Seattle Genetics)

No conflicts of interest to disclose: JGB

Open Access This article is distributed under the terms of the Creative Commons Attribution License which permits any use, distribution, and reproduction in any medium, provided the original author(s) and the source are credited.

\section{References}

1. Barr AR, Gergely F (2007) Aurora-A: the maker and breaker of spindle poles. J Cell Sci 120:2987-2996

2. Fu J, Bian M, Jiang Q, Zhang C (2007) Roles of Aurora kinases in mitosis and tumorigenesis. Mol Cancer Res 5:1-10

3. Marumoto T, Honda S, Hara T, Nitta M, Hirota T, Kohmura E et al
(2003) Aurora-A kinase maintains the fidelity of early and late mitotic events in HeLa cells. J Biol Chem 278:51786-51795

4. Dutta-Simmons J, Zhang Y, Gorgun G, Gatt M, Mani M, Hideshima T et al (2009) Aurora kinase A is a target of Wnt/beta-catenin involved in multiple myeloma disease progression. Blood 114:2699-2708

5. Evans R, Naber C, Steffler T, Checkland T, Keats J, Maxwell C et al (2008) Aurora A kinase RNAi and small molecule inhibition of Aurora kinases with VE-465 induce apoptotic death in multiple myeloma cells. Leuk Lymphoma 49:559-569

6. Tomita M, Toyota M, Ishikawa C, Nakazato T, Okudaira T, Matsuda $\mathrm{T}$ et al (2009) Overexpression of Aurora A by loss of CHFR gene expression increases the growth and survival of HTLV-1-infected T cells through enhanced NF-kappaB activity. Int J Cancer 124:26072615

7. Ye D, Garcia-Manero G, Kantarjian HM, Xiao L, Vadhan-Raj S, Fernandez MH et al (2009) Analysis of Aurora kinase A expression in CD34(+) blast cells isolated from patients with myelodysplastic syndromes and acute myeloid leukemia. J Hematop 2:2-8

8. Bischoff JR, Anderson L, Zhu Y, Mossie K, Ng L, Souza B et al (1998) A homologue of Drosophila aurora kinase is oncogenic and amplified in human colorectal cancers. EMBO J 17:3052-3065

9. Wang X, Zhou YX, Qiao W, Tominaga Y, Ouchi M, Ouchi T et al (2006) Overexpression of aurora kinase A in mouse mammary epithelium induces genetic instability preceding mammary tumor formation. Oncogene 25:7148-7158

10. Fukasawa K, Wiener F, Vande Woude GF, Mai S (1997) Genomic instability and apoptosis are frequent in $\mathrm{p} 53$ deficient young mice. Oncogene 15:1295-1302

11. Katayama H, Sasai K, Kawai H, Yuan ZM, Bondaruk J, Suzuki F et al (2004) Phosphorylation by aurora kinase A induces Mdm2mediated destabilization and inhibition of p53. Nat Genet 36:55-62

12. Hata T, Furukawa T, Sunamura M, Egawa S, Motoi F, Ohmura N et al (2005) RNA interference targeting aurora kinase a suppresses tumor growth and enhances the taxane chemosensitivity in human pancreatic cancer cells. Cancer Res 65:2899-2905

13. Hirota T, Kunitoku N, Sasayama T, Marumoto T, Zhang D, Nitta M et al (2003) Aurora-A and an interacting activator, the LIM protein Ajuba, are required for mitotic commitment in human cells. Cell 114: 585-598

14. Marumoto T, Hirota T, Morisaki T, Kunitoku N, Zhang D, Ichikawa $\mathrm{Y}$ et al (2002) Roles of aurora-A kinase in mitotic entry and G2 checkpoint in mammalian cells. Genes Cells 7:1173-1182

15. Gorgun G, Calabrese E, Hideshima T, Ecsedy J, Perrone G, Mani M et al (2010) A novel Aurora-A kinase inhibitor MLN8237 induces cytotoxicity and cell-cycle arrest in multiple myeloma. Blood 115: $5202-5213$

16. Manfredi MG, Ecsedy JA, Chakravarty A, Silverman L, Zhang M, Hoar KM et al (2011) Characterization of Alisertib (MLN8237), an investigational small-molecule inhibitor of aurora A kinase using novel in vivo pharmacodynamic assays. Clin Cancer Res 17:76147624

17. Dees EC, Cohen RB, von Mehren M, Stinchcombe TE, Liu H, Venkatakrishnan K et al (2012) Phase I study of Aurora A kinase inhibitor MLN8237 in advanced solid tumors: safety, pharmacokinetics, pharmacodynamics, and bioavailability of two oral formulations. Clin Cancer Res 18:4775-4784

18. Kelly KR, Nawrocki ST, Espitia CM, Zhang M, Yang JJ, Padmanabhan S et al (2012) Targeting Aurora A kinase activity with the investigational agent alisertib increases the efficacy of cytarabine through a FOXO-dependent mechanism. Int J Cancer 131:26932703

19. Mahadevan D, Qi WQ, Cooke L, Lui XB, Persky DO, Rimsza LM et al (2009) Targeting Aurora kinase in aggressive B-cell NonHodgkin's lymphomas. Blood 114(22):Abstract 284

20. Friedberg J, Mahadevan D, Jung J, Cebula E, Persky D, Lossos I et al (2013) Phase II study of alisertib, a selective aurora A 
kinase inhibitor, in relapsed and refractory aggressive B- and Tcell non-Hodgkin lymphoma. J Clin Oncol. doi:10.1200/JCO. 2012.46.8793

21. Goldberg SL, Fenaux P, Craig MD, Gyan E, Lister J, Kassis J et al (2010) Phase 2 study of MLN8237, an investigational Aurora A Kinase (AAK) inhibitor in patients with Acute Myelogenous Leukemia (AML) or Myelodysplastic Syndromes (MDS). Blood (ASH Annual Meeting Abstracts) 116: abstract 3273

22. Mahadevan D, Stejskal A, Cooke LS, Manziello A, Morales C, Persky DO et al (2012) Aurora A inhibitor (MLN8237) plus vincristine plus rituximab is synthetic lethal and a potential curative therapy in aggressive B-cell non-Hodgkin lymphoma. Clin Cancer Res 18: 2210-2219

23. Qi W, Cooke LS, Liu X, Rimsza L, Roe DJ, Manziolli A et al (2011) Aurora inhibitor MLN8237 in combination with docetaxel enhances apoptosis and anti-tumor activity in mantle cell lymphoma. Biochem Pharmacol 81:881-890

24. Cervantes A, Elez E, Roda D, Ecsedy JA, Macarulla T, Venkatakrishnan K et al (2012) Phase I pharmacokinetic/ pharmacodynamic study of MLN8237 - an investigational, oral, selective, Aurora A Kinase inhibitor - in patients with advanced solid tumors. Clin Cancer Res 18:4764-4774

25. National Cancer Institute (2006) Common terminology criteria for adverse events version 3.0 (NCI-CTCAE). http://ctep.cancer.gov/ protocoldevelopment/electronic_applications/docs/ctcaev3.pdf. Accessed 11 September 2013

26. Cheson BD, Pfistner B, Juweid ME, Horning SJ, Coiffier B, Gascoyne RD et al (2006) Recommendations for revised response criteria for malignant lymphoma. J Clin Oncol (ASCO Annual Meeting) 24:18S (June 20 Supplement): abstract 7507

27. Cheson BD, Pfistner B, Juweid ME, Gascoyne RD, Specht L, Horning SJ et al (2007) Revised response criteria for malignant lymphoma. J Clin Oncol 25:579-586
28. Durie BG, Harousseau JL, Miguel JS, Blade J, Barlogie B, Anderson $\mathrm{K}$ et al (2006) International uniform response criteria for multiple myeloma. Leukemia 20:1467-1473

29. Hallek M, Cheson BD, Catovsky D, Caligaris-Cappio F, Dighiero G, Dohner $\mathrm{H}$ et al (2008) Guidelines for the diagnosis and treatment of chronic lymphocytic leukemia: a report from the International Workshop on Chronic Lymphocytic Leukemia updating the National Cancer Institute-Working Group 1996 guidelines. Blood 111:5446-5456

30. Matulonis UA, Sharma S, Ghamande S, Gordon MS, Del Prete SA, Ray-Coquard I et al (2012) Phase II study of MLN8237 (alisertib), an investigational Aurora A kinase inhibitor, in patients with platinumresistant or -refractory epithelial ovarian, fallopian tube, or primary peritoneal carcinoma. Gynecol Oncol 127:63-69

31. Sharma S, Kurzrock R, Gouw L, Hong DS, Jones K, Zhou X et al (2011) Phase I dose-escalation study of the investigational Aurora A kinase (AAK) inhibitor MLN8237 as an enteric-coated tablet (ECT) formulation in patients with nonhematologic malignancies. J Clin Oncol 29(15_suppl):Abstract 3094

32. Hook KE, Garza SJ, Lira ME, Ching KA, Lee NV, Cao J et al (2012) An integrated genomic approach to identify predictive biomarkers of response to the aurora kinase inhibitor PF-03814735. Mol Cancer Ther 11:710-719

33. Qi W, Spier C, Liu X, Agarwal A, Cooke LS, Persky DO et al (2013) Alisertib (MLN8237) an investigational agent suppresses Aurora A and $\mathrm{B}$ activity, inhibits proliferation, promotes endo-reduplication and induces apoptosis in T-NHL cell lines supporting its importance in PTCL treatment. Leuk Res 37:434-439

34. Mahadevan D, Unger JM, Spier CM, Persky DO, Young F, LeBlanc $M$ et al (2013) Phase 2 trial of combined cisplatin, etoposide, gemcitabine, and methylprednisolone (PEGS) in peripheral T-cell non-Hodgkin lymphoma: Southwest Oncology Group Study S0350. Cancer 119:371-379 